\title{
Intuition and Professional Competence: Intuitive Versus Rational Forecasting of the Stock Market
}

\author{
Christian Harteis • Hans Gruber
}

Received: 28 July 2007 / Accepted: 28 November 2007 /

Published online: 28 December 2007

(C) Springer Science + Business Media B.V. 2007

\begin{abstract}
This article argues that intuition is a crucial component of professional competence, and provides empirical evidence to support this claim. It was found that in most cases intuitive predictions of stock market development are better than rationally justified ones and that experts predict more precisely than novices on a descriptive data level. The discussion links these findings to the literature about expertise and intuition. Research on professional expertise theoretically indicates intuition as a crucial component of that expertise. This article focuses on the exercise of intuition in the domain of investment. Stock market investment decisions rely on forecasts of market development. As complete information is not available, entirely rational decisions cannot be made, and it becomes necessary to rely on intuition. An overview of theories on intuition are presented followed by discussion of an empirical study in which 32 persons of varying experience in the stock market used intuition as well as rational justifications to predict stock rates.
\end{abstract}

Keywords Decision making $\cdot$ Expertise $\cdot$ Intuition $\cdot$ Rationality $\cdot$

Stock market forecast

\section{Intuition and Professional Practice}

Intuition refers to the domain-specific capability to reach an appropriate decision without deliberately balancing various alternatives and without reflecting on a task (Myers 2002). Intuition makes use of knowledge-resources secured through individuals' professional experiences, but of which they may not be necessarily aware. This intuition is held to give experts advantage over persons who do not act intuitively (Hogarth 2001). One domain through which intuition can be investigated is its role as a component of professional performance in the stock market forecasting. A typical task in the domain of investment is to forecast developments

C. Harteis $(\bowtie) \cdot$ H. Gruber

University of Regensburg, Institute of Education, 93040 Regensburg, Germany

e-mail: christian.harteis@paedagogik.uni-regensburg.de 
on the stock market. Even though it is a daily task of investment professionals, it can be done in different ways, depending on time pressure and on the need to rationally defend one's decisions. In consequence, there is ample variance of individual experiences and of the degree of conscious assumptions. Stock markets are an important area of the economy and of management. Stock prices represent the anticipated economic achievement potential of a listed enterprise. It is an important question whether effective forecasting economic development is an area of rationality or intuition. Thus, forecasting tasks are appropriate means to investigate intuition (Klein 2003). The idea of rational decision-making as a decisive modality of management has a long tradition in theories of management and business (Hitt et al. 2005). However, during recent years, increased interest has been directed towards intuition as an effective modality of management (e.g. Robbins 2005).

\section{The Role of Intuition in the Field of Economy}

Frantz (2005), when analyzing the history of economic thought since Adam Smith, showed that intuition plays a role in the range of economic theories. Indeed, it seems to be a misconception that management and business decisions are completely based on rational choices. Full rationality in decision making requires unlimited cognitive resources and capabilities (Selten 2002). As human knowledge processing is quite limited (e.g., human short-term memory processes an average of $7 \pm 2$ information units [Miller 1956]), it is acknowledged that managers cannot consider all dimensions, facets and details of a given complex problem. Despite these restrictions, managers are able to reasonably and successfully solve complex business problems. They operate within the restrictions of bounded rationality, a model developed by Simon (1957). He described decision making as a process that seeks an appropriate, but not necessarily optimal, solution to a problem. The appropriateness of a solution results from the goal variable (i.e. to win a chess match) to be achieved. The process of searching for a solution stops when the goal variable is reached. Simon (1957) calls this solution a "satisfycing" solution, which is a combination of satisfying and sufficiency.

Evidence exists that relying on intuition can improve decision making under the constraints of bounded rationality. Intuitive decision making is defined as "the primarily subconscious process of identifying a decision and selecting a preferred alternative" (Hitt et al. 2005, 311). Weick and Sutcliffe (2001) describe managers' core competence as the ability to cope with surprising, unexpected and new challenges. The crucial capabilities they detected are, first, the grasp for danger or critical development in a very early stage, and, second, the capability to decide intuitively in an appropriate way to stop a danger development. A study of managers in small- and medium-sized companies found a positive correlation between managers' intuitive decision style and their enterprises' economic financial and non-financial performance (Sadler-Smith 2004). This study reflects the findings of similar studies conducted by Agor (1986), Andersen (2000), Isenberg (2001), Khatri and $\mathrm{Ng}$ (2000) or Westcott (1968), which all identified positive correlations between intuitive decision tendencies and performance. Similarly, Davis and Davis (2003) investigated school principals in California and also confirmed the importance and 
efficiency of intuitive decision making in management. This suggests that intuition is perhaps a broadly based capacity that can be deployed in a range of fields of human activity. These studies reported a saving of time and cognitive resources as the most important advantage of intuitive decisions. Thus, quick reactions are possible and resources remain available for other important management activities. So, the development of intuition is of importance to understanding what constitutes effective work performance.

\section{Cognitive Background: The Two Systems Theory of Information Processing}

In their early work, Kahneman and Tversky (1972) investigated the phenomenon that people estimate things badly in areas where they are usually considered to be competent. These authors subsequently developed the theory of two parallel operating systems of information processing (Sloman 2002), which is widely applied in business and managerial decision-making research (e.g. Dane and Pratt 2007; Sadler-Smith and Shefy 2004). Referring to the theory's assumption, that individuals' engage in different working modes, various approaches of decisionmaking research proposed that there are two parallel and permanent operating information processing systems (Bruner 1962; Hogarth 2005; Kahneman and Frederick 2002; Sloman 2002). Although they use different terminologies, these approaches agree in principle with the comparison of a mode operating deliberately, rationally and analytically with a mode working associatively, intuitively and tacitly. Hammond (1993) claims that these two operation modes can be located at a continuum of consciousness: the intuitive mode is on the unconscious side of the continuum, and the rational mode is on the conscious one. The border between these two modes exercises variably on the continuum between the two poles. That means that intuitive decisions can be conscious (i.e., if somebody follows a gut feeling) and rational decisions can be partly unconscious (e.g., if somebody follows a given order) (Gladwell 2005).

Importantly, the concept "that two independent systems are at work depends critically on the fact that the perception and the knowledge are maintained simultaneously" (Sloman 2002, p. 385). For instance, when observing pictures with pretend lines of differing length only on the basis of three-dimensional illusions, subjects show a compulsion to agree that the presented lines are of similar length but simultaneously try to find reasons for the perception of differing lengths. Similar simultaneous beliefs of contradicting statements could be observed in arguing or concluding with probabilities (Tversky and Kahneman 1983).

Opinions differ as to how the intuitive and the rational thinking modes influence human behaviour. In one direction, evidence suggests that the rational system can overrule the intuitive system in the case of ex-post reflecting of failing actions (Epstein et al. 1992). Conversely, Sloman (2002) argued that in each rational decision, intuitive shares appear because the intuitive system works associative and, thus, quicker than each rational consideration. Hence, intuitive traces influences (even) perception, and, by that, every decision that is independent of the mode. Allinson and Hayes (1996) developed a questionnaire that identifies a general thinking style (Cognitive Style Index). Such a perspective assumes a general 
preference for either intuitive or rational decision making. More test inventories exist following a similar idea: Epstein et al. (1996) and their REI-questionnaire, Agor's AIM (1984), and the Myers Briggs Type Indicator (Briggs and Myers 1976). These instruments were applied in several studies that investigated the advantage of intuitive thinking styles in management (Agor 1986; Davis and Davis 2003; SadlerSmith 2004). Even if these studies proved the effectiveness of an intuitive thinking style, the knowledge base of intuition must still be explained and considered in accounts of expertise.

\section{Intuition and Expertise}

Research on expertise usually describes the development of individual knowledge structures during the progress from novice to expert. This approach derives from studies of chess that investigated the role of memory for extraordinary performances of perception and recognition (Chase and Simon 1973a, b). Findings suggested that decision-making behaviour, in reality, is not always completely rational (Simon 1955), and experts have recognized patterns in complex arrangements that enable them to respond spontaneously. On this basis, the idea of intuition as recognition became established (de Groot 1986). Indeed, in Dreyfus and Dreyfus' (1986) fivestep model for the development of expertise, the highest level of expertise is that of intuitive action, which does not demand concentration, reflection or awareness. Their theory indicated that intuition uses rich knowledge of which people are no longer aware. This is sometimes referred to as tacit knowledge (Reber 1993). However, this knowledge developed by experience and eventually by enculturation in a professional domain. A well-known example they quoted is of chicken sexers who work at chicken farms and who are able to distinguish male and female chickens that are only a few days old when rational descriptions fail. This profession was imported from Japan, where there is a long tradition of chicken sexing, and an apprenticeship program that focuses on the long process of implicit learning by doing and enculturation, and by referring to the Zen philosophy (Lunn 1948). Qualified sexers can identify the gender of 2,000 chickens in one hour with 98 percent accuracy (Biederman and Shiffar 1987), but they are unable to report on their decision ratio, as they are just doing it (Schroeder 1933) intuitively (Dreyfus and Dreyfus 1986).

Eraut (1994) in reviewing research on professional expertise noted that the developed structures of explicable (i.e. declarative and procedural) knowledge only describe one (important) aspect of professional performance, but that intuition is an important supplement. He defined intuition as "not only pattern recognition but also rapid responses to developing situations...based on the tacit application of tacit rules. These rules may not be explicit or capable of reasoned justification, but their distinctive feature is that of being tacit at the moment of use" (Eraut 2000, p. 127). Intuition in this way may permit heuristics to be rapidly deployed, and likely arises through the merging of complex knowledge patterns, developed during learning (Reber 1993) or by the automation and development of routines (Eraut 1994). The

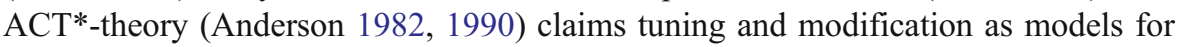
cognitive processes underlying the transition from explicit to implicit knowledge, in 烈 Springer 
ways that are analogous to descriptions of intuition. Nonaka and Takeuchi (1995) described the processes of internalization as a way of tacitly transforming explicable knowledge and enculturation as a way of mediating implicit knowledge in the context of the professional working life.

Klein (2003) discussed the effect of mental models and pattern recognition when he tried to explain professionals' capacities to make appropriate decisions under constraints. These mental models and patterns are a result of mental simulations of action scripts that professionals experience in their career. If a simulation results positively, a mental model develops that can guide future fast decisions. It seems that intuition "is based on extensive experience both in analysis and problem solving and in implementation and to the extent that the lessons of experience are logical and well-founded, then so is the intuition" (p. 19). Baron and Ensley (2006) demonstrated how experienced entrepreneurs outclass novices in identifying potential business opportunities. This is due to a personal cognitive framework that was developed through individuals' experience, which facilitates spontaneous pattern recognition - the basis of intuitive decision making.

In this way, construing intuition as a component of expertise implies a development theory for the capability of intuitive decision making. Hence, the expertise approach offers a learning perspective on intuition: Intuition is grounded on knowledge that is developed by explicit and implicit processes of professional learning (Gladwell 2005; Klein 2003; Myers 2002), but not on innate capabilities. Thus, expertise is an educational account of intuition.

\section{Intuition and the Stock Market}

Although decisions for investment in certain stocks might be proposed as a rational process, the prerequisites for a rational choice situation are compromised because objective and complete information is not always available e.g. on the future development. Additionally, several alternatives may offer similar conditions that make a rationally informed decision impossible. Hence, intuition becomes relevant for stock market decisions.

A typical task for stock brokers involves forecasting economic developments. On the one hand, customers must be consulted about ways to invest money; on the other hand, the profitability of a financial institution depends on the quality of its own investment predictions and decisions. A decision to buy stocks depends on predictions of the likely economic success of an enterprise. Thus, assumptions referring to a single enterprise must be formulated, as well as estimations on entire business sectors. Certainly, some objective information exists on enterprises and market competition. Of course, one can expect that professionals in this field have gained experience from many market observations over a number of years. However, there is simply not enough information to create an accurate forecast. Thus, the ability to use intuition to make an appropriate decision is very important because the possibility to reach a solution through wholly means is limited. Some even hold that rational decision-making can be seen as obstacles that overlap with implicit heuristics that have been learned and created through years of experience (Reber 1993). Explicit knowledge, which rational considerations refer to, and implicit 
knowledge, which intuitive decisions refer to are different cognitive modalities. The latter is not necessarily approachable by consciousness. Thus, rational considerations overshadow intuitive ones, as soon as a person's attention is focused on rationality (Bastick 2003; Dienes and Perner 2002).

As foreshadowed, someone who is forced to deliver a rational justification for a forecast is predicted to perform worse than somebody who is free from these constraints (Kahneman and Frederick 2002). This is because of the lack of information, which is an unchangeable feature of a forecast. The force to justify a forecast rationally affects conservative and careful forecasts, which can be referred to as explicit knowledge. Yet, the lack of a need for justification does not place the priority on rational considerations because it allows the usage of implicit knowledge. Thus, intuitive forecasts are supposed to be more accurate - measured through the final and effective development of the concerned values - than forecasts that have to be justified rationally. From a theoretical viewpoint, the following two research questions result:

1. Are intuitive forecasts better than rationally justified ones, both referring to single stocks and to aggregate values (e.g., DAX - the German stock market index)? The distinction between single and aggregate values makes sense, because single values can be influenced by singular events to a higher extent than aggregated values. Aggregate values can be seen as cumulated economic quantity.

2. Do experts and novices differ in the quality of their intuitive and rationally justified forecasts? As stock market forecasts were characterised as an issue of expertise, differences between experts and novices should be observable.

\section{Method}

Design and Sample

Two groups ( $n=16$ each) of subjects were compared, differing in the "level of expertise" (experts, novices). The groups were defined as a split-half of a sample of 32 subjects dealing with stock market issues. The split between the groups was based on the years of experience on the stock market, as a device to compare the two groups, as much literature refers to differences between more or less expert workers. The group of novices were those subjects with up to 4 years of experience; experts were those with 4 to 20 years of experience. All members of the expert group were drawn from professionals in the bank or investment domain. All subjects had to give both intuitive and rationally justified forecasts. In total, $N=32$ persons ( 23 men and 9 women) participated voluntarily by responding to an invitation. All the female participants belonged to the group of novices. Some subjects did not answer certain questions on the questionnaire, so some calculations have different sample sizes.

Instrument and Procedure

In an online questionnaire, subjects forecasted the development of five important German stock market values nine months in advance: DAX, Allianz, DaimlerChrysler, 
Infineon Technologies, Karstadt Quelle. Additionally, the subjects forecasted the price of fuel (i.e. regular unleaded) and the exchange rate of $€$ vs US\$. All values were forecasted in Euros except the DAX, which was scaled in index points, and the exchange rate of the US\$, which was indicated as the price for $1 €$ in US\$. The subjects were to put the expected number in an input mask. For each intuitive forecast, the answering time was limited to $15 \mathrm{~s}$, which generated considerable time pressure. For rationally justified forecasts, no time limit was set, and subjects explicitly had to write down rational justifications for their decisions. This follows the basic assumption of this study: if subjects are forced to justify forecasts rationally, intuitive ideas are suppressed. Under time pressure, however, intuitive forecasts are forced.

Randomized test sequences guaranteed that intuitive and rationally justified forecasts were equally distributed in the sample, except for the DAX forecast, which had to be forecasted, at first, intuitively and, at the end of the questionnaire, rationally justified by all subjects. Due to the time pressure for intuitive forecasts, the reaction time was tested at the end of the questionnaire in order to control possible influences of reaction time on the quality of the forecasts. That means that for the DAX, a within-subject design with repeated measures was realised; for all other values the study covered a between-subject design.

All subjects had to respond to a reaction test, which consisted of reading information on the monitor and delivering an input to the computer. Time was measured from the delivery of the information until the complete input of an answer. The purpose of this reaction test is to control this variable, because intuitive forecasts had to be done under considerable time pressure, which is advantageous to people with quick reactions compared to slow subjects.

The quality of the forecasts was estimated by comparison with the effective stock prices nine months later. The less the forecasts differed from the effective price, the higher the quality of the forecasts. Differences between forecasts and effective prices were further analysed.

\section{Analyses}

Data analysis commenced with the calculation of the differences between forecasted and effective stock prices and their descriptive statistics. The research questions were answered by analyses of variance ( $t$-test, ANOVA) and correlation analyses (Pearson). Effect sizes were calculated for each test.

\section{Results}

Table 1 shows the stock prices at the beginning and at the end of the study. The 'beginning' column contains the prices at the time when the experiment started. The 'end' column shows the prices at the time which has to be predicted (i.e. 9 months later). The selected economic indicators performed different during that period. The value of four indicators increased, two decreased, and one ended at the same price as it had at the beginning of the experiment.

All analyses refer to the difference between the forecasts and the effective value at the end of the study. Table 2 documents the accuracy of the forecasts (i.e., the 
Table 1 Stock prices at the beginning at the end of the study

\begin{tabular}{lll}
\hline Value & Beginning & End \\
\hline DAX & $4,256.08 \mathrm{pts}$ & $5,282.13 \mathrm{pts}$ \\
Allianz & $97.15 €$ & $125.25 €$ \\
DaimlerChrysler & $35.25 €$ & $43.24 €$ \\
Infineon Technologies & $7.91 €$ & $7.82 €$ \\
Karstadt Quelle & $7.60 €$ & $11.70 €$ \\
Fuel & $1.219 €$ & $1.219 €$ \\
Exchange rate $1 €$ vs. US \$ & 1.3646 US \$ & 1.1801 US \$ \\
\hline
\end{tabular}

difference between predicted value and effective stock rate nine months later), both for rationally justified and intuitive forecasts. Positive means indicate that the forecast was above the effective value; negative means indicate that the effective value was higher than forecasted. In four cases, the mean accuracy of intuitive forecasts was higher than of the rational forecasts, in two cases the rational forecasts were more accurate in average.

Before focusing on intuitive and rationally justified forecasts, the influence of reaction time is analysed in order to control a possible influence of reaction time on the forecast accuracy. Table 3 shows the correlation coefficients between forecast accuracy and subjects' reaction time. No significant correlation could be found. This indicates that the forecast accuracy was independent from subjects' speed of responding to an input mask which has been an important feature of the experiment.

Forecast accuracy was checked for group differences between rationally justified and intuitive forecasts by two-sided $t$-tests. In the case for the DAX value, which was measured for each subject repeatedly, a $t$-test for dependent samples was calculated. In all other cases, a $t$-test for independent samples was calculated (see Table 4), because the subject made - following a system internal random generator either an intuitive or a rationally justified forecast. For significant differences, the effect size $d$ was calculated. Means and standard deviations are shown in Table 2. The differing degrees of freedom result from subjects omitting some questions.

In both cases of significant differences, the intuitive forecasts were closer to the effective price than the rationally justified ones. Finally, Table 5 shows the comparison of experts and novices and the results of a $2 \times 2$ factorial analysis of variance (data shown only for main effect "level of expertise"). The only significant difference between experts and novices was found at the forecast of the Allianz stock, which was predicted more accurate by experts.

Table 2 Accuracy of rational and intuitive forecasts measured as difference from effective stock price. Means and standard deviations

\begin{tabular}{lll}
\hline Value & $\begin{array}{l}\text { Mean difference/SD rational } \\
\text { forecasts }\end{array}$ & $\begin{array}{l}\text { Mean difference/SD intuitive } \\
\text { forecasts }\end{array}$ \\
\hline DAX & $-1,086.87 / 916.19(n=32)$ & $-939.01 / 832.99(n=32)$ \\
Allianz & $-26.30 / 9.56(n=18)$ & $-25.17 / 9.14(n=13)$ \\
DaimlerChrysler & $-8.62 / 3.88(n=17)$ & $-8.55 / 4.13(n=14)$ \\
Infineon Technologies & $+0.31 / 1.44(n=14)$ & $+0.57 / 2.17(n=17)$ \\
Karstadt Quelle & $-2.18 / 2.61(n=13)$ & $-3.11 / 2.84(n=17)$ \\
Fuel & $+0.02 / 0.11(n=14)$ & $+0.02 / 0.17(n=16)$ \\
Exchange rate 1 $€$ vs. US $\$$ & $+0.14 / 0.09(n=16)$ & $-0.01 / 0.10(n=15)$ \\
\hline
\end{tabular}


Table 3 Pearson correlation between forecast accuracy and reaction time

$d f=31$

$* p<.05$

\begin{tabular}{ll}
\hline Value & $r$ (reaction time) \\
\hline DAX intuitive & -0.29 \\
DAX rationale & -0.28 \\
Allianz & 0.09 \\
DaimlerChrysler & -0.03 \\
Infineon Techn. & 0.05 \\
Karstadt Quelle & -0.08 \\
Fuel & 0.19 \\
Exchange rate $1 €$ vs US \$ & 0.26 \\
\hline
\end{tabular}

\section{Discussion}

The discussion focuses on methodological aspects of the study and relates the findings with the context of the literature on expertise and intuition.

\section{Question 1: Are Intuitive Forecasts Better than Rationally Justified Ones?}

From a theoretical standpoint, intuition was found to enhance the quality of forecasts on the stock market. For the empirical design, a procedure was selected that tends to exclude rational considerations from intuitive forecasts by implementing time pressure. This is a typical strategy for investigating intuitive decisions (Wahl 1990). Intuitive forecasts are supposed to be better than the rational ones because substantial information for providing correct forecasts is missing. Thus, rational considerations, which tend to balance different positions and options, are supposed to be more biased than intuitive forecasts. During the measures, each forecast that had to be justified rationally, started with a presentation of basic information. This information consisted of a chart illustrating a 12-month market history.

All subjects had to provide an intuitive and a rationally justified forecast of the most important aggregated stock value: the German stock index DAX. As Table 2 shows, the intuitive forecasts were better than the rationally justified ones in most cases. So far, the theoretical assumption was confirmed. However, this finding can be discussed critically when considering the gap between the forecasts and the effective DAX value. The average forecasts were 4,195.13 (rationally justified) and 4,342.99 (intuitive), whereas the effective value reached 5,282 index points. Both, rationally justified decisions and intuitive decisions substantially differed from the "true" score (21 and 18\%, respectively).

Table 4 Test of differences between rational and intuitive forecasts

Two sided $t$-test for ${ }^{\text {a }}$ dependent and independent samples n.s Not significant, $d$ Cohen's $d$

\begin{tabular}{lllll}
\hline Value & \multicolumn{2}{l}{$t$-test $t$ significance } & Df & $D$ \\
\hline DAX & & & \\
Allianz & -2.10 & $p<0.05$ & 31 & -0.52 \\
DaimlerChrysler & $<1$ & n.s. & 28 & \\
Infineon Technologies & $<1$ & n.s. & 29 & \\
Karstadt Quelle & $<1$ & n.s. & 29 & \\
Fuel & $<1$ & n.s. & 29 & \\
Exchange rate $1 €$ vs. US \$ & 4.51 & $p<.001$ & 29 & \multirow{2}{*}{1.62} \\
& & & & \\
\hline
\end{tabular}


Table 5 Comparison of experts and novices referring to the quality of their forecasts: Means (SD)

\begin{tabular}{|c|c|c|c|c|c|}
\hline Value & Experts & novices & $F(1,29)$ & Significance & $d$ \\
\hline DAX & $\begin{array}{l}r:-928.56(679.18) \\
i:-735.62(282.90)\end{array}$ & $\begin{array}{l}r:-1,245.17(1,104.55) \\
i:-1,142.52(1,125.01)\end{array}$ & $<1$ & n.s. & \\
\hline Allianz & $\begin{array}{l}r:-23.61(8.75) \\
i:-20.97(5.73)\end{array}$ & $\begin{array}{l}r:-28.70(10.11) \\
i:-31.89(10.08)\end{array}$ & 5.44 & $p<.05$ & 0.82 \\
\hline DaimlerChrysler & $\begin{array}{l}r:-9.10(3.34) \\
i:-6.91(2.74)\end{array}$ & $\begin{array}{l}r:-8.29(4.36) \\
i:-11.50(4.85)\end{array}$ & 1.23 & n.s. & \\
\hline Infineon Technologies & $\begin{array}{l}r:+0.21(1.31) \\
i:+0.77(1.58)\end{array}$ & $\begin{array}{l}r:+0.45(1.71) \\
i:+0.39(2.67)\end{array}$ & $<1$ & n.s. & \\
\hline Karstadt Quelle & $\begin{array}{l}r:+1.00(2.25) \\
i:+2.72(3.09)\end{array}$ & $\begin{array}{l}r:+4.08(2.05) \\
i:+3.44(2.73)\end{array}$ & 3.11 & n.s. & \\
\hline Fuel & $\begin{array}{l}r:-0.04(0.10) \\
i:+0.01(0.12)\end{array}$ & $\begin{array}{l}r:+0.07(0.10) \\
i:+0.03(0.24)\end{array}$ & 1.20 & n.s. & \\
\hline Exchange rate $€ / \$$ & $\begin{array}{l}r:+0.16(0.10) \\
i:-0.08(0.09)\end{array}$ & $\begin{array}{l}r:+0.11(0.08) \\
i:+0.03(0.09)\end{array}$ & $<1$ & n.s. & \\
\hline
\end{tabular}

n.s. Not significant, $r$ rational forecasts, $i$ intuitive forecasts, $d$ Cohen's $d$

These differences can be interpreted as indicators of the bad quality of forecasting in general. However, the judgement of the quality criteria for the forecasts averts the issue that intuition is a component of professional competence, because it is at best an economic debate. Objective information was not available for the forecast. The purpose of this study was to investigate differences between intuitive and rationally justified forecasts.

Alternatively, the results can be read in a way that rational considerations suggested a careful prediction, which is evident when regarding the development of the DAX the year before the study took place. In relation to that period, the increase of the DAX during the experimental period is extraordinary - even if the later development of the DAX remained at such a level of increase. Thus, the difference between the forecasts and the effective rate was highly influenced by accidental incidents in the experimental period. More interesting for this study is the difference between intuitive and rationallyjustified forecasts, which remains independent from accidental influences. Wide information was presented to the subjects before they made their rationally justified DAX forecast. There is evidence that the presentation of data material influences estimations by defining a reference class (Gigerenzer et al. 1997), so the rationally justified forecasts may be biased in that direction. However, it must be considered that the intuitive forecast of the DAX was given before the rationally justified one.

For the other forecasts (i.e. Allianz, DaimlerChrysler, Infineon Technologies, Karstadt Quelle, US\$, and fuel), subjects had to provide randomly distributed forecasts that are either intuitive or rationally justified. Whereas Allianz, DaimlerChrysler, Infineon Technologies, Karstadt Quelle, and fuel cost are single economical items, the Euro and the US\$ (as currencies) can also be interpreted as an aggregated economic item. Noteworthy, the intuitive and rationally justified forecasts of the US\$ also differed significantly, and again the intuitive forecasts were closer to the effective price than the rationally justified ones.

The relative deviations are much lower than in the case of the DAX, which cannot be explained by the absolute figures (the DAX is a value measured in thousands of points; exchange rates between currencies are measured in decimal places). The 
rationally justified forecasts differ by $12 \%$ from the effective exchange rate; the intuitive forecasts differ by average of only $1 \%$. Thus, the intuitive dollar forecast achieved almost perfect accuracy. In the same way, the same questions can be challenged regarding the explanatory power of figures, which now - in contrast to the DAX - differ just by decimal places.

Does the difference between intuitive and rationally justified forecasts matter? It does at least in the way that the differences are statistically significant. The effect size (Cohen's $d$ ) in the DAX forecast is medium-large $(d=0.52)$; the one in the US\$ is very large $(d=1.62)$. Nearly identical intuitive forecasts were responsible, so that even small sums of differences are significant. It was noted that these above estimations might be biased through reference classes introduced into the measurement setting. The exchange rate of the US\$ varied within quite a large range during the year before the study was conducted, but the effective exchange rate lies on the lower end of the range of this development. If an orientation at the reference of the presented chart occurred, the rational forecasts should have been in the upper range, because the dollar was at a higher level for most of the presented year and - particularly - at the moment of the investigation.

In contrast to DAX and US\$, no significant differences between intuitive and rationally justified forecasts were found for the other predictions, which referred to single economic items - either corporate or raw material. An explanation is that aggregated values depend on a more complex and manifold net of influences than single values. Thus, intuition as capability to come to an appropriate business decision in opaque or partly unknown solutions (Cappon 1994) has a larger effect on aggregated values than on single values.

However, even if no significant difference between intuitive and rational forecasts can be found, some differences in the quality of the forecasts occurred. There are forecasts to three stock values that show a relatively high difference to the effective values. The forecasts of Allianz show a distance of $21 \%$ (i.e. rational) and $20 \%$ (i.e. intuitive) to the effective market price, similar to the forecasts of DaimlerChrysler (i.e. both forecasts 20\%). Karstadt Quelle ended in differences of 19\% (i.e. rational) and $27 \%$ (i.e. intuitive). In contrast, Infineon Technologies was predicted quite well (i.e. $4 \%$ deviance on rational, $7 \%$ on intuitive forecasts), and the price of fuel was predicted almost exactly (i.e. $2 \%$ in both kind of forecasts). Possible reasons for these differences in the prognostic quality can be found in the domain of economy. In the debate on intuition, the fact remains that on single values there is no significant difference between intuitive and rational forecasts, except on aggregated values.

\section{Question 2: Do Experts and Novices Differ?}

Theories on intuition as a component of professional competence suggest the experts are superior to novices because of their experience and their relevant implicit and explicit knowledge (Reber 1993). As the results show, in most cases there is no significant difference between experts' and novices' accuracy (see Table 5). The only exception is the Allianz value forecast, which the experts predicted with significantly more accuracy. Notably, the experts' forecasts were more accurate when they were intuitive than when they were rational, whereas the novices achieved a better result with rational predictions. However, the experts' predictions 
were both closer to the effective Allianz stock price than the novices' predictions. As the effect size for the differences between experts and novices is quite high $(d=$ 0.82), one can conclude from the findings for this one stock value that the differences in quality in the forecasts are a result of the expertise factor.

For further discussion of the differences between experts and novices, the focus needs to address descriptive results. In total, seven economic items had to be predicted. For each item, rational as well as intuitive predictions had to be made. Table 5 clearly shows that in 10 of the 14 forecasts, the experts were more accurate than the novices in forecasting effective values.

Striking results referring the two aggregated values could not be found here. The first aggregated value, the DAX, was forecasted more precisely by the experts in both kinds of prediction, whereas the US\$ was better predicted by the novices in both forecasts. Whilst intuitive and rational forecast of aggregated values significantly differed, the experts could not attain considerable advantage of their superior knowledge and experience for their forecasts of DAX and US\$. As discussed above, the accuracy of the forecasts for the exchange rate between $€$ and US\$ reached a very high level, especially the intuitive forecasts. Thus, the difference between experts and novices referring to their rational and intuitive US\$ forecasts may be neglected even on a descriptive data level.

The fact that experts and novices did not significantly differ supports the theory of intuition, because it constructs intuition as a thinking style that is not necessarily connected to experience alone (Allinson and Hayes 1996). However, even if there is some evidence that the tendency of deciding intuitively might also be connected to personal traits, it is quite difficult to explain why domain knowledge developed during the professional career or experience on stock market observation should not impact intuitive decisions. Even if stable personal traits - for instance risk-taking readiness or tolerance of ambiguity - influence the tendency to intuitively decide (or rationally), differences in the knowledge base between experts and novices influence the tendency (and probably also the outcome) of decision making. Apart from this, it is a fundamental question whether decision-making tendencies and thinking styles generally can be interpreted independently from concrete situations and, therefore, domains.

Within the investigation, time pressure was supposed to force intuitive forecasts by excluding rational considerations as much as possible. That means that those subjects who were slower at processing the questions were possibly at a disadvantage in this study. A reaction test, which measured the time between presentation of information and the input of a complete answer, aimed to determine whether the intuitive forecasts demanded too much. No significant correlation between reaction time and the accuracy of forecasts was found.

\section{Conclusion}

The relevance of intuition for management theories and decision making in the domain of the stock market was proposed here. Customers expect that professionals in bank institutions or investment consultancies can rely on a huge stock of implicit and explicit knowledge and, thus, that professionals in this domain do not decide 
accidentally when giving advice to their customers. Investment advice is always connected to (perhaps implicit) forecasts of market development. However, market forecasts cannot refer to complete information, because there is always some crucial information missing that is necessary to determine factors objectively. Thus, intuition is an important component of professional competence in the domain of stock market because it allows individuals to act appropriately in situations when they lack information.

The central assumption was set that intuition promotes the quality of forecasts on the stock market. The empirical findings partly confirm this assumption for aggregated stock values. In these cases, the intuitive forecasts were significantly closer to the effective values than the rationally justified forecasts. In fact, the US\$ was intuitively predicted with almost perfect accuracy. Similar results were not found for single stock values. This may be because single values are subject to singular irregular influences more than aggregated values. However, the selection of the involved stocks included large companies, which are less susceptible to accidental incidents and enterprises from different market areas in order to cover a wide market.

It is interesting that experts and novices did not perform on different quality levels. However, it has to be considered that the number of participants was quite low. Thus, conclusions can be drawn carefully only. There were arguments that this suggests intuition is a personal trait. It would be promising to replicate the study with larger differences in experience between novices and experts. Another possibility is to recruit subjects not (only) from bank institutes, which have a variety of professional tasks, but from a fund society for the expert group.

By choosing the stock market as a setting for research into intuition in the openresult manner of a forecast study, this exercise led to interesting insights. Many influences might affect the effective result of such a study. Some of them may be accidental; some of them may come from contexts that are not related with intuition. However, all these influences affect the size of deviation from effective values. Differences between intuitive and rationally justified forecasts, however, were independent from those influences. It seems worthwhile to conduct replication studies in order to check the reliability of this study and to exclude other potential influences. The next step of research should focus on how intuition as a component of professional competence develops along an occupational career. Such research could enhance understanding in the field of professional learning. This contribution emphasizes the importance of intuition as component of professional competence from a theoretical perspective and the study provides empirical evidence.

\section{References}

Agor, W. H. (1984). Intuitive management. Englewood Cliffs: Prentice-Hall.

Agor, W. H. (1986). The logic of intuitive decision making: A research based approach for top management. Westport: Quorum Books.

Allinson, C., \& Hayes, J. (1996). The Cognitive Style Index: A measure of intuition-analysis for organisational research. Journal of Management Studies, 33, 119-35.

Andersen, J. A. (2000). Intuition in managers. Are intuitive managers more effective? Journal of Managerial Psychology, 15(1), 46-67.

Anderson, J. R. (1982). Acquisition of cognitive skill. Psychological Review, 89, 369-406. 
Anderson, J. R. (1990). The adaptive character of thought. Hillsdale: Lawrence Erlbaum.

Baron, R. A., \& Ensley, M. D. (2006). Opportunity recognition as detection of meaningful patterns: Evidence from comparisons of novice and experienced entrepreneurs. Management Science, 52(9), $1331-1344$.

Bastick, T. (2003). Intuition. Evaluating the construct and its impact on creative thinking. Kingston: Stoneman \& Lang.

Biederman, I., \& Shiffar, M. M. (1987). Sexing day-old chicks. Journal of Experimental Psychology: Learning, Memory, and Cognition, 13, 640-645.

Briggs, K. C., \& Myers, I. B. (1976). The Myers Briggs type indicator. Palo Alto: Consulting Psychologists Press.

Bruner, J. (1962). On knowing. Cambridge: Harvard University Press.

Cappon, D. (1994). Intuition and management. Research and application. Westport: Quorum Books.

Chase, W. G., \& Simon, H. A. (1973a). The mind's eye in chess. In W. G. Chase (Ed.) Visual information processing (pp. 215-281). New York: Academic Press.

Chase, W. G., \& Simon, H. A. (1973b). Perception in chess. Cognitive Psychology, 4(1), 55-81.

Dane, E., \& Pratt, M. G. (2007). Exploring intuition and its role in managerial decision making. Academy of Management Review, 32(1), 33-54.

Davis, S. H., \& Davis, P. B. (2003). The intuitive dimensions of administrative decision making. Oxford: Scarecrow.

de Groot, A. D. (1986). Intuition in chess. International Computer Chess Association Journal, 9, 67-75.

Dienes, Z. \& Perner, J. (2002). A theory of the implicit nature of implicit learning. In R. M. French \& A. Cleeremans (Ed.) Implicit learning and consciousness (pp. 68-92). Sussex: Psychology Press.

Dreyfus, H. L., \& Dreyfus, S. E. (1986). Mind over machine. The power of human intuition and expertise in the era of the computer. New York: The Free Press.

Epstein, S., Lipson, A., Holstein, C., \& Huh, E. (1992). Irrational reactions to negative outcomes: Evidence for two conceptual systems. Journal of Personality and Social Psychology, 62, 328-339.

Epstein, S., Pacini, R., Denes-Rej, V., \& Heier, H. (1996). Individual differences in intuitive-experiential and analytical-rational thinking styles. Journal of Personality and Social Psychology, 71, 390-405.

Eraut, M. (1994). Developing professional knowledge and competence. London: Routledge Falmer.

Eraut, M. (2000). Non-formal learning and tacit knowledge in professional work. British Journal of Education, 70, 113-36.

Frantz, R. (2005). Two minds. Intuition and analysis in the history of economic thought. New York: Srpinger.

Gigerenzer, G., Hoffrage, U., \& Kleinbölting, H. (1997). Probabilistic mental models: A Brunswikian theory of confidence. In W. M. Goldstein \& R. M. Hogarth (Eds.), Research on judgement and decision making (pp. 95-143). Cambridge: Cambridge University Press.

Gladwell, M. (2005). Blink. The power of thinking without thinking. New York: Little, Brown and Company.

Hammond, K.-R. (1993). Natural decision making from a Brunswikian viewpoint. In G. A. Klein, J. Oras, anu, R. Calderwood, \& C. E. Zsambok (Eds.) Decision making in action: Models and methods (pp. 205-227). Westport, CT, US: Ablex Publishing.

Hitt, M. A., Black, J. S., \& Porter, L. W. (2005). Management. Upper Saddle River: Pearson Prentice Hall. Hogarth, R. M. (2001). Educating intuition. Chicago: University Press.

Hogarth, R. M. (2005). Deciding analytically or trusting your intuition? The advantages and disadvantages of analytic and intuitive thought. In T. Betsch, \& S. Haberstroh (Eds.) The routines of decision making (pp. 67-82). Mahwah: Lawrence Erlbaum.

Isenberg, D. (2001). How senior managers think. Harvard Business Review, 62(6), 81-90.

Kahneman, D., \& Frederick, S. (2002). Representativeness revisited: Attribute substitution in intuitive judgment. In T. Gilovich, D. Griffin, \& D. Kahneman (Eds.) Heuristic and biases. The psychology of intuitive judgment (pp. 49-81). Cambridge: Cambridge University Press.

Kahneman, D., \& Tversky, A. (1972). Subjective probability: A judgment of representativeness. Cognitive Psychology, 3, 430-454.

Khatri, N., \& Ng, H. A. (2000). The role of intuition in strategic decision making. Human Relations, 53 (1), 57-86.

Klein, G. (2003). Intuition at work. New York: Doubleday.

Lunn, J. H. (1948). Chick sexing. American Scientist, 36, 280-287.

Miller, G. A. (1956). The magical number seven, plus or minus two: Some limits on our capacity for processing information. Psychological Review, 63, 81-97.

Myers, D. G. (2002). Intuition. Its powers and perils. New Haven: Yale University Press. 
Nonaka, I., \& Takeuchi, H. (1995). The knowledge creating company. How Japanese companies create the dynamics of innovation. Oxford: Oxford University Press.

Reber, A. S. (1993). Implicit learning and tacit knowledge. An essay on the cognitive unconscious. New York: Oxford University Press.

Robbins, S. P. (2005). Essentials of organizational behavior (8th.th ed.). Upper Saddle River: Pearson Prentice Hall.

Sadler-Smith, E. (2004). Cognitive style and the management of small and medium sized enterprises. Organization Studies, 25(2), 155-181.

Sadler-Smith, E., \& Shefy, E. (2004). The intuitive executive: understanding and applying 'gut feel' in decision-making. Academy of Management Executive, 18(4), 76-91.

Schroeder, C. H. (1933). How tell the baby chick's sex. Everybody's Poultry Journal, 289, 293-297.

Selten, R. (2002). What is bounded rationality? In G. Gigerenzer, \& R. Selten (Eds.) Bounded rationality. The adaptive toolbox (pp. 13-35). Cambridge: MIT Press.

Simon, H. A. (1955). A behavioural model of rational choice. Quarterly Journal of Economics, 69, 99-118.

Simon, H. A. (1957). Models of man. New York: Wiley.

Sloman, S. A. (2002). Two systems of reasoning. In T. Gilovich, D. Griffin, \& D. Kahneman (Eds.) Heuristic and biases. The psychology of intuitive judgment (pp. 379-396). Cambridge: Cambridge University Press.

Tversky, A., \& Kahneman, D. (1983). Extensional versus intuitive reasoning: The conjunction fallacy in probability judgment. Psychological Review, 90, 293-315.

Wahl, D. (1990). Handeln unter Druck [Acting under pressure]. Wiesbaden: Deutscher Universitätsverlag.

Weick, K. E., \& Sutcliffe, K. M. (2001). Managing the unexpected. San Francisco: Jossey-Bass.

Westcott, M. R. (1968). Psychology of intuition. A historical, theoretical, and empirical inquiry. New York: Holt, Rinehart \& Winston. 